\title{
A ESTETIZAÇÃO DA POLÍTICA E A PERSONALIDADE AUTORITÁRIA: REFLEXÕES A PARTIR DE WALTER BENJAMIN E THEODOR ADORNO
}

\author{
Emanuelle Beserra de Oliveira \\ Hildemar Luiz Rech \\ Lia Freitas Oliveira
}

\begin{abstract}
RESUMO
Partindo da famosa tese de Walter Benjamin de que o resultado lógico do fascismo é a introdução da estética na vida política, percebemos como os recursos estéticos são captados e transformados em veículos motores para o espetáculo do fascismo. Dentro desse espetáculo destaca-se o homem autoritário diagnosticado por Theodor Adorno. A compreensão desses fenômenos devem ser ancoradas em bases psicanalíticas, pois o horror político representado pelo fascismo emerge das repressões libidinais que a sociedade industrial impõe.
\end{abstract}

Palavras-Chaves: Benjamin. Adorno. Fascismo. Personalidade autoritária.

\section{THE AESTHETICIZATION OF POLICY AND AUTHORITY PERSONALITY: REFLECTIONS FROM WALTER BENJAMIN AND THEODOR ADORNO}

\begin{abstract}
Starting from Walter Benjamin's famous thesis that the logical result of fascism is the introduction of aesthetics into political life, we realize how aesthetic resources are captured and transformed into motor vehicles for the spectacle of fascism. Within this spectacle, the authoritarian man diagnosed by Theodor Adorno stands out. The understanding of the phenomena must be anchored on psychoanalytic bases, since the political horror represented by fascism emerges from the libidinal repressions that industrial society imposes on us.
\end{abstract}

Keywords: Benjamin. Adorno. Fascism. Authoritarian personality.

\footnotetext{
Doutoranda em Educação pela UFC, na linha Filosofia e Sociologia da Educação. Pesquisadora do Grupo “Educação, Teoria Crítica e Filosofia Contemporânea” (Cnpq). Brasileira, residente em Fortaleza-CE. Email: manubazik@hotmail.com

Professor Titular da FACED. Doutor em Ciências Sociais pela Universidade Estadual de

Campinas. Brasileiro, residente em Fortaleza-CE. Email: hluizrech@gmail.com

Doutoranda em Educação pela UFC, na linha Filosofia e Sociologia da Educação.

Pesquisadora do Grupo "Walter Benjamin e a Filosofia Contemporânea" (Cnpq). Brasileira, residente em Fortaleza-CE. Email: liafreitasoliveira@gmail.com
} 


\section{Introdução}

Nos últimos anos do século $X X I$, vimos a crescente difusão de posicionamentos neofascistas e a eleição de diversos políticos, em várias partes do mundo, de extrema direita. Tal diagnóstico requer um novo olhar para as democracias que veem nascer em seu seio uma postura autoritária e centralizadora de opiniões.

Os pensadores da Escola de Frankfurt estiveram em alerta sobre os perigos oferecidos no interior das democracias liberais e do sistema capitalista. O discurso autoritário e padronizador do capitalismo se encontra nos meandros de sua estrutura. Sendo assim, o estado de exceção torna-se uma ferramenta de manutenção das relações de propriedade diante das crises cíclicas. Walter Benjamin esteve atento, desde a década de 1920, às mobilizações políticas da classe média reacionária na Alemanha em consonância com a extrema direita que surgia como ideologia de caráter contrarrevolucionário. Nessa investigação minuciosa dos aspectos teóricos, ideológicos e culturais do fascismo, Benjamin mostrou os mecanismos fascistas através do fenômeno da estetização da política. Os meios de comunicação em massa, surgidos após o desenvolvimento da reprodutibilidade técnica, foram um importante elemento para o caráter propagandístico do fascismo. Além disso, o aspecto místico da estetização dos elementos da guerra, o culto à técnica e à nação, são fatores fundamentais presentes nas ideologias autoritárias do século passado. Entretanto, tais elementos ainda se encontram presentes no século XXI a partir de novas roupagens e performances.

Apesar da democracia ser uma forma de organização política amplamente aceita, e vista como a mais aberta à participação popular, as orientações autoritárias não desapareceram dentro desses sistemas. Daí a necessidade de buscar a compreensão da origem do fascismo e o modo como ele se manifesta atraindo uma grande massa que adere a este movimento sem questionar suas intenções.

Doutoranda em Educação pela UFC, na linha Filosofia e Sociologia da Educação. Pesquisadora do Grupo “Educação, Teoria Crítica e Filosofia Contemporânea” (Cnpq). Brasileira, residente em Fortaleza-CE. Email: manubazik@hotmail.com

Professor Titular da FACED. Doutor em Ciências Sociais pela Universidade Estadual de

Campinas. Brasileiro, residente em Fortaleza-CE. Email: hluizrech@gmail.com

Doutoranda em Educação pela UFC, na linha Filosofia e Sociologia da Educação. residente em Fortaleza-CE. Email: liafreitasoliveira@gmail.com 
Theodor Adorno, em sua pesquisa sobre a personalidade autoritária (1950), alerta para o nascimento de um novo tipo de humano na sociedade moderna, o homem autoritário que é hostil com uma ampla variedade de minorias, porém sem nenhuma base racional que sustente essa sua hostilidade.

Sob o fascismo, o progresso tornou-se um retrocesso por meio da ideologia. O nazismo recusou a modernidade do lluminismo enquanto abraçava mecanismos modernos para produzir e promulgar a sua ideologia, expressa por meio de filmes e do rádio, controlados pelo governo. O fascismo sempre regride a um passado mítico, enquanto usa meios mecânicos para controlar o presente.

A análise do aspecto humano da liberdade e do autoritarismo nos leva à consideração da questão principal, a saber, o papel desempenhado pelos fatores psicológicos como forças ativas no processo social. Adorno aponta que a explicação da tendência ao autoritarismo é psicanalítica. Com base nos estudos de Freud em psicologia de massas (1921), Adorno foi capaz de dar conta das condições psicológicas para a ascensão de um líder carismático, bem como o arsenal de gestos usados pelo líder para enfeitiçar e mobilizar. O principal argumento deste trabalho foi que certos fenômenos de grupo e comportamentos sociais podem ser derivados de experiências da primeira infância, como a relação de um filho com um pai autoritário e inacessível. Ao não confrontar essa figura, o filho passa a idolatrar figuras de autoridade, objetivando se transformar nessa mesma figura.

A investigação acerca dos elementos místicos do fascismo e da personalidade autoritária mantém relações profundas com o clima cultural geral do modo capitalista de organização socioeconômica, que condiciona o homem a uma eterna condição de competitividade, condicionando-o a um retorno à barbárie. Por isso, faz-se necessário compreender as patologias da cultura: particularmente o autoritarismo irracional e suas potencialidades que se manifestam diariamente em regimes que se dizem democráticos.

Doutoranda em Educação pela UFC, na linha Filosofia e Sociologia da Educação. Pesquisadora do Grupo “Educação, Teoria Crítica e Filosofia Contemporânea” (Cnpq). Brasileira, residente em Fortaleza-CE. Email: manubazik@hotmail.com

Professor Titular da FACED. Doutor em Ciências Sociais pela Universidade Estadual de

Campinas. Brasileiro, residente em Fortaleza-CE. Email: hluizrech@gmail.com

Doutoranda em Educação pela UFC, na linha Filosofia e Sociologia da Educação.

Pesquisadora do Grupo "Walter Benjamin e a Filosofia Contemporânea" (Cnpq). Brasileira, residente em Fortaleza-CE. Email: liafreitasoliveira@gmail.com 


\title{
10 fascismo e a estetização da guerra
}

Em seu ensaio Teorias Do Fascismo Alemão: sobre a coletânea Guerra e Guerreiros editada por Ernst Jünger (1930), Walter Benjamin faz uma crítica à coleção organizada por Jünger - já conhecido como um importante nome da literatura belicista alemã -, que trazia textos de ex-soldados da Primeira Guerra Mundial, todos caracterizados por um forte misticismo bélico e glorificação da guerra. $O$ interesse de Benjamin, na análise dessa coletânea, era entender o processo de ascensão do fascismo na Alemanha e seu componente ideológico.

Já no início do texto, Benjamin faz referência a uma frase dita por Léon Daudet, jornalista e líder do Partido Monarquista francês, sobre o Salão do Automóvel:

\begin{abstract}
"L'automobile c'est la guerre". O que estava na raiz dessa surpreendente associação de palavras era a ideia de uma aceleração dos instrumentos técnicos, seus ritmos, suas fontes de energia etc., que não encontram em nossa vida pessoal nenhuma utilização completa e adequada e, no entanto, lutam por justificar-se. Na medida em que renunciam todas as interações harmônicas, esses instrumentos se justificam pela guerra [...]. (BENJAMIN, 1994, 61).
\end{abstract}

O desenvolvimento acelerado do progresso técnico, juntamente com o aumento das massas, faz com que o capitalismo não tenha um fim para onde escoar seus excessos. A crise que se instaura coloca a guerra como resposta para a utilização da força humana e da técnica, simultaneamente, para justificar todo o contrassenso de uma sociedade altamente racionalizada pela tecnologia e que se aniquila através da mobilização das pulsões libidinais regressivas. A finalidade primordial da estetização da política é a guerra. Isso se dá porque é pela guerra que os meios técnicos de uma sociedade profundamente padronizada se colocam como mantenedoras das relações com a propriedade privada.

O fenômeno do surgimento das massas está intimamente ligado ao processo de proletarização como consequência das transformações técnicas advindas do modo de produção industrial. Todo o excesso do capitalismo conduz

Doutoranda em Educação pela UFC, na linha Filosofia e Sociologia da Educação. Pesquisadora do Grupo "Educação, Teoria Crítica e Filosofia Contemporânea" (Cnpq). Brasileira, residente em Fortaleza-CE. Email: manubazik@hotmail.com

Professor Titular da FACED. Doutor em Ciências Sociais pela Universidade Estadual de

Campinas. Brasileiro, residente em Fortaleza-CE. Email: hluizrech@gmail.com

Doutoranda em Educação pela UFC, na linha Filosofia e Sociologia da Educação.

Pesquisadora do Grupo "Walter Benjamin e a Filosofia Contemporânea" (Cnpq). Brasileira, residente em Fortaleza-CE. Email: liafreitasoliveira@gmail.com 
à barbárie e à catástrofe e tal condição poderia ser um território propício para processos revolucionários ${ }^{1}$. O fascismo surge no terreno do capitalismo como resposta sobre essa intensificação, pois organiza e disciplina as massas para a manutenção da estrutura socioeconômica².

Benjamin entende que um vínculo místico com a tecnologia faz parte da natureza das relações sociais burguesas: "a sociedade burguesa não pode deixar de separar, na medida do possível, a dimensão técnica da chamada dimensão espiritual" (1994, 61). Essa separação esvazia a tecnologia do seu componente de materialidade social e trata a técnica como um produto neutro dessa estrutura. Esse desvinculamento da tecnologia do seu caráter sociocultural engendra a sua mistificação.

No seu famoso ensaio sobre a reprodutibilidade técnica, Benjamin analisa que o surgimento das técnicas de reprodução em massa empreendida pelo capitalismo já possui em si certos princípios que serão potencializados pelo fascismo dentro de seus objetivos específicos. Em alguns esboços e anotações (1938-40) para esse ensaio, Benjamin traz um trecho da palestra de Carl Schimitt Sobre a era das neutralizações políticas (1929).

\begin{abstract}
As invenções dos séculos XV e XVI tinham efeitos libertadores, individualistas e rebeldes; a invenção da arte da impressão levou à liberdade de imprensa. Hoje as invenções técnicas são meios de uma dominação monstruosa das massas [...] a decisão entre liberdade ou servidão não se encontra na técnica enquanto técnica. [...] De seus princípios não resulta nem um questionamento político, nem uma resposta política" A pergunta de Schimitt é, portanto: que política é forte suficiente para se utilizar da técnica como um meio de the dar um sentido definitivo? Sua resposta é: apenas uma que politize todos os
\end{abstract}

\footnotetext{
${ }^{1}$ A preocupação de Benjamin, desde os anos de 1920, com tais temáticas se desenvolveu a partir da eclosão de Revolução Alemã (1918-1919) e sua consequente repressão violenta pelo Partido Social-Democrata Alemão. A partir desses eventos, Benjamin percebe o processo gradativo de ascensão da extrema direita na Alemanha e muitos de seus escritos desse período surgem como uma análise das bases teóricas e ideológicas dessas manifestações políticas na cultura alemã.

2 "A proletarização crescente da humanidade contemporânea e a formação crescente de massas são dois aspectos de um mesmo acontecimento. O fascismo tenta organizar as novas massas proletárias sem tocar as relações de posse para cuja abolição elas tendem." (BENJAMIN, 1994, 91).
}

Doutoranda em Educação pela UFC, na linha Filosofia e Sociologia da Educação.

Pesquisadora do Grupo "Educação, Teoria Crítica e Filosofia Contemporânea" (Cnpq). Brasileira, residente em Fortaleza-CE. Email: manubazik@hotmail.com

Professor Titular da FACED. Doutor em Ciências Sociais pela Universidade Estadual de

Campinas. Brasileiro, residente em Fortaleza-CE. Email: hluizrech@gmail.com

Doutoranda em Educação pela UFC, na linha Filosofia e Sociologia da Educação.

Pesquisadora do Grupo "Walter Benjamin e a Filosofia Contemporânea" (Cnpq). Brasileira, residente em Fortaleza-CE. Email: liafreitasoliveira@gmail.com 
âmbitos da vida na mesma medida em que foram neutralizados por meio do comércio e da técnica. $(2013,144)$.

A pergunta de Benjamin é a chave para compreendermos uma possibilidade de empreender a técnica não dentro de parâmetros societários de dominação política e econômica, mas pensar a força que a técnica pode ter como auxílio para as massas se mobilizarem e buscarem a sua própria libertação. Segundo o autor não é possível pensar em transformações políticas sem compreender e se apossar das transformações históricas que se apresentam. Entretanto, as mídias de massa são utilizadas tanto em favor da ideologia dominante do capital, como quando, nos momentos de crise, se apresentam como ferramentas essenciais do fascismo para a propagação de seus mecanismos de disciplinarização das massas.

Os meios de comunicação de massa são um importante aparato para a propaganda fascista, tendo em vista que é através deles que o fascismo permite as massas atingirem sua expressão, mas nunca seu direito (BENJAMIN, 2013, 91). Essa expressão não se constitui de maneira autêntica, na qual a massa que na análise benjaminiana coincide com a classe proletária - se expressaria como corpo coletivo em busca de seus direitos, ou até mesmo de uma ruptura revolucionária. A expressão se dá a partir de uma performance reificada, sem substancialidade, em que não existe autonomia, mas os desejos da massa se ligam completamente aos desejos da ideologia dominante.

Os mecanismos da reprodutibilidade técnica, em seu cerne, criam um equilíbrio entre as massas e os aparelhos. O fascismo se utiliza dessa potencialidade para concretizar a mistificação que tem como fundo um desejo de identificação primevo. A guerra, então, seria a apoteose para a qual se direciona o desenvolvimento de estetização da política que empreende o fascismo, pois é a mobilização total de todos os dispositivos de poder do capital. Em um texto de 1930 chamado $A$ mobilização total, Jünger diz:

Doutoranda em Educação pela UFC, na linha Filosofia e Sociologia da Educação. Pesquisadora do Grupo “Educação, Teoria Crítica e Filosofia Contemporânea” (Cnpq). Brasileira, residente em Fortaleza-CE. Email: manubazik@hotmail.com

Professor Titular da FACED. Doutor em Ciências Sociais pela Universidade Estadual de

Campinas. Brasileiro, residente em Fortaleza-CE. Email: hluizrech@gmail.com

Doutoranda em Educação pela UFC, na linha Filosofia e Sociologia da Educação.

Pesquisadora do Grupo "Walter Benjamin e a Filosofia Contemporânea" (Cnpq). Brasileira, residente em Fortaleza-CE. Email: liafreitasoliveira@gmail.com 


\begin{abstract}
Nós tocamos levemente no lado técnico da mobilização total, cujo aperfeiçoamento pode ser seguido desde os primeiros recrutamentos empreendidos pelo governo da Convenção, desde a reorganização das forças armadas promovida por Scharnhorst, até os programas de armação dinâmica dos últimos anos de guerra, nos quais os países se transformaram em fábricas gigantescas que produziam exércitos em esteiras rolantes, para enviá-los, dia e noite, aos campos de batalha, onde um consumo bélico, que se tornou igualmente muito mecânico, assumiu o papel do consumidor mercantil. Por mais que a monotonia dessa visão, que lembra a precisa operação de uma turbina alimentada a sangue, perturbe de modo vexaminoso o ânimo heróico, não pode haver, com efeito, qualquer dúvida sobre o conteúdo simbólico que mora em seu íntimo: aqui se manifesta uma conseqüência rigorosa, a marca dura de uma época cujo elemento fundamental é a guerra. (JÜNGER, 2002, 198-199).
\end{abstract}

Essa é a "mobilização total" que possui o seu início no interior das fábricas e finda nas trincheiras. O campo de batalha e as armas são a concretização das fábricas. Benjamin cita Jünger na coletânea Guerra e Guerreiros: "O caminho percorrido era estreito e perigoso, mas era um caminho que conduzia ao futuro" (1994, 69). A ideia vazia do progresso pelo progresso só pode encontrar justificativa moral na guerra e a tecnologia passa a ser exaltada como ideal. A guerra torna-se um espetáculo, uma apoteose dessa ideologia, a consumação de suas intenções.

Benjamin correlaciona tal situação ao mesmo princípio da "arte pela arte": perspectiva estética que desvincula a arte de seu contexto sócio-político. A guerra como justificação moral é o que leva à compreensão da "beleza da guerra". Nos textos dos soldados da coletânea de Jünger, existe uma exaltação dos símbolos da guerra como mais importantes do que a vivência da guerra em si mesma. O culto ao uniforme e o engrandecimento do "caráter planetário" da guerra vivida apresenta o que Benjamin denominou de "entusiasmo pubertário" (1994, 62), uma visão regressiva e infantil sobre a vivência da destruição.

Os textos fazem referência à Primeira Guerra como "a última guerra", perdida pela Alemanha e transformada em abstração metafísica. Aquele que perde a guerra não a possui mais, por isso transformaram-na em um ideal, a fim de resguardar o passado em uma vivência abstrata:

Doutoranda em Educação pela UFC, na linha Filosofia e Sociologia da Educação. Pesquisadora do Grupo “Educação, Teoria Crítica e Filosofia Contemporânea” (Cnpq). Brasileira, residente em Fortaleza-CE. Email: manubazik@hotmail.com

Professor Titular da FACED. Doutor em Ciências Sociais pela Universidade Estadual de

Campinas. Brasileiro, residente em Fortaleza-CE. Email: hluizrech@gmail.com

Doutoranda em Educação pela UFC, na linha Filosofia e Sociologia da Educação.

Pesquisadora do Grupo "Walter Benjamin e a Filosofia Contemporânea" (Cnpq). Brasileira, residente em Fortaleza-CE. Email: liafreitasoliveira@gmail.com 
A guerra como abstração metafísica, professada pelo novo nacionalismo, é unicamente a tentativa de dissolver na técnica, de modo místico e imediato, o segredo de uma natureza concebida em termos idealistas, em vez de utilizar e explicar esse segredo, por um desvio, através da construção de coisas humanas. (BENJAMIN, 1994, 70).

Os autores falam sobre a passagem dos mortos da guerra para uma Alemanha "eterna", uma espécie de tratamento da guerra como um ritual de passagem que mantem o sentido de nação. Benjamin observa que, em nenhum momento, os autores dos textos tratam a guerra de frente, as descrições apresentadas não passam de um esvaziamento abstrato de todos os elementos da destruição. A visão mística da guerra e dos aparatos técnicos que a sustentam tem como fundo a competitividade do capitalismo, tendo em vista que existe uma espécie de competição da destruição. A batalha material que culmina na guerra de gases com destruição de proporções absurdas ${ }^{3}$, é vista com maravilhamento, o que significa um contrassenso: tal perspectiva destrói, inclusive, o ideal de heroísmo ligado à guerra.

Benjamin compreende que a técnica precisa ser produzida a partir da consciência sobre seu caráter materialista e antropológico e deve ser concebida como extensão humana e manifestação das potencialidades da humanidade. $O$ capitalismo e sua relação instrumental com a natureza culmina na guerra como resposta ao procedimento destrutivo desse sistema. "No piloto de um avião carregado com bombas de gás concentram-se todos os poderes - 0 de privar 0 cidadão da luz, do ar e da vida - que na paz estão divididos entre milhares de chefes de escritório" (BENJAMIN, 1994, 72). O imperialismo e as relações de exploração e divisão de classe já empreendem a privação que a guerra consuma

\footnotetext{
3 "Os autores omitiram o fato de que a batalha de material, na qual alguns deles vislumbram a mais alta revelação da existência, coloca fora de circulação os miseráveis emblemas do heroísmo, que ocasionalmente sobreviveram à grande guerra. A luta de gases, pela qual os colaboradores do livro demonstram tão pouco interesse, promete dar à guerra futura um caráter esportivo que superará as categorias militares e colocará as ações guerreiras sob o signo do recorde". (BENJAMIN, 1994, 62-63).
}

Doutoranda em Educação pela UFC, na linha Filosofia e Sociologia da Educação.

Pesquisadora do Grupo "Educação, Teoria Crítica e Filosofia Contemporânea" (Cnpq). Brasileira, residente em Fortaleza-CE. Email: manubazik@hotmail.com

Professor Titular da FACED. Doutor em Ciências Sociais pela Universidade Estadual de

Campinas. Brasileiro, residente em Fortaleza-CE. Email: hluizrech@gmail.com

Doutoranda em Educação pela UFC, na linha Filosofia e Sociologia da Educação.

Pesquisadora do Grupo "Walter Benjamin e a Filosofia Contemporânea" (Cnpq). Brasileira, residente em Fortaleza-CE. Email: liafreitasoliveira@gmail.com 
permanentemente. A autoalienação que provoca essa sistemática do capital "atingiu tal grau que se lhe torna possível vivenciar a sua própria aniquilação como um deleite estético de primeira ordem" (BENJAMIN, 2013, 94). O fascismo é a quintessência desse deleite estético pela morte.

Portanto, a estetização da política empreendida pelo fascismo se estabelece através de um processo de mistificação de símbolos esvaziados, que em nada se vinculam com a materialidade e historicidade do contexto vivido. $\mathrm{O}$ indivíduo, tomado por esses discursos, ancora sua frágil subjetividade nesses elementos: a guerra, a farda de combate, ou simplesmente o líder. Nessa relação entre mecanismos do capitalismo que desembocam no fascismo, vimos que Benjamin mostra como o contexto da reprodutibilidade técnica é fundamental no desenvolvimento dessa estetização, tendo em vista que é principalmente através das mass medias que o líder fascista cria uma relação de identificação com as massas que deseja controlar. Tal líder se coloca como veículo da expressividade das massas: "Para ele, a salvação encontra-se em deixar as massas atingirem sua expressão (de modo algum o seu direito)" (BENJAMIN, 1994, 91). Essa conexão é construída e explorada através da propaganda como meio fundamental para a construção da imagem do líder. Este expressa, através de sua performance de irracionalidade, tudo o que o indivíduo comum gostaria de ser, mas não pode por uma série de padrões impostos pelo status quo civilizatório.

Theodor Adorno desenvolve de forma aprofundada as questões psicossociais que conectam tais elementos do fascismo com os indivíduos em seus estudos sobre os aspectos da propaganda fascista e a personalidade autoritária. Vimos que, segundo Benjamin, a finalidade primordial da estetização da política é a guerra. A relação entre o progresso técnico e a guerra traz aos indivíduos atomizados uma sensação de potência, controle e pertencimento. Entretanto, o contrassenso da guerra está exposto, segundo Adorno, no seguinte fato: as finalidades concretas do fascismo vão contra o interesse material

Doutoranda em Educação pela UFC, na linha Filosofia e Sociologia da Educação. Pesquisadora do Grupo “Educação, Teoria Crítica e Filosofia Contemporânea” (Cnpq). Brasileira, residente em Fortaleza-CE. Email: manubazik@hotmail.com

Professor Titular da FACED. Doutor em Ciências Sociais pela Universidade Estadual de

Campinas. Brasileiro, residente em Fortaleza-CE. Email: hluizrech@gmail.com

Doutoranda em Educação pela UFC, na linha Filosofia e Sociologia da Educação.

Pesquisadora do Grupo "Walter Benjamin e a Filosofia Contemporânea" (Cnpq). Brasileira, residente em Fortaleza-CE. Email: liafreitasoliveira@gmail.com 
daqueles que o seguem e aí está sua irracionalidade. O fascismo caminha para o aniquilamento total, sua irracionalidade não rompe com as forças repressoras civilizatórias, mas caminha para a eliminação do próprio indivíduo que adere e se identifica com tais discursos.

Doutoranda em Educação pela UFC, na linha Filosofia e Sociologia da Educação. Pesquisadora do Grupo "Educação, Teoria Crítica e Filosofia Contemporânea" (Cnpq). Brasileira, residente em Fortaleza-CE. Email: manubazik@hotmail.com

Professor Titular da FACED. Doutor em Ciências Sociais pela Universidade Estadual de Campinas. Brasileiro, residente em Fortaleza-CE. Email: hluizrech@gmail.com Doutoranda em Educação pela UFC, na linha Filosofia e Sociologia da Educação. residente em Fortaleza-CE. Email: liafreitasoliveira@gmail.com 


\section{0 fascismo e a Personalidade Autoritária}

Os filósofos de Frankfurt sempre refletiram sobre os efeitos do autoritarismo e suas consequências, principalmente as atrocidades cometidas na Segunda Guerra Mundial com a ascensão do governo nazista. Erich Fromm foi o primeiro a analisar o fenômeno da personalidade autoritária do ponto de vista da psicologia. Fromm, juntamente com W. Reich, começou a estudar o problema do fascismo na década de 1930 no Instituto de Pesquisa Social (Institut für Sozialforschung) em Frankfurt. Fromm esperava que houvesse uma ligação direta entre os adeptos do fascismo e a personalidade autoritária.

O fascismo promove o espetáculo, fato que leva a Walter Benjamin (1936) a constatar a estetização da política. O Estado fascista se alinha aos mass media para propagar os discursos ilógicos e irracionais que sustentam esses tipos de regimes. Dentro do fascismo há um culto explícito de uma ordem que é baseada na violência e nas práticas autoritárias. Ao falar da estetização da política, também devemos falar da estetização do político, essa figura do líder autoritário que promove um "show" ao proferir suas ideias, que apesar das distorções são "conscientemente planejada e organizada" (ADORNO, 2015, 143).

Em 1944, Adorno e Horkheimer já apontam, em sua obra Dialética do esclarecimento, a questão do autoritarismo, presente em seu texto "Elementos do anti-semitismo: limites do esclarecimento". Verificando as ameaças feitas ao povo judeu, os autores tentam estabelecer um perfil ao indivíduo que possuía predisposição a aderir posicionamentos fascistas. Tal estudo que se inicia nessa obra se consolida em 1950 quando da publicação de seu texto "A personalidade autoritária"4, no qual Adorno (1989) afirma que a temática central do trabalho é um conceito relativamente novo - o surgimento de uma espécie "antropológica" que podemos chamar de homem autoritário.

\footnotetext{
${ }_{4}$ Obra resultado da pesquisa que se inicia em 1944 na Universidade de Berkeley, com o propósito de desvendar as características do homem que tende ao fascismo.

Doutoranda em Educação pela UFC, na linha Filosofia e Sociologia da Educação. Pesquisadora do Grupo “Educação, Teoria Crítica e Filosofia Contemporânea” (Cnpq). Brasileira, residente em Fortaleza-CE. Email: manubazik@hotmail.com

Professor Titular da FACED. Doutor em Ciências Sociais pela Universidade Estadual de

Campinas. Brasileiro, residente em Fortaleza-CE. Email: hluizrech@gmail.com

Doutoranda em Educação pela UFC, na linha Filosofia e Sociologia da Educação.

Pesquisadora do Grupo "Walter Benjamin e a Filosofia Contemporânea" (Cnpq). Brasileira, residente em Fortaleza-CE. Email: liafreitasoliveira@gmail.com
} 
Já no ensaio de 1951, "Teoria Freudiana e o Padrão da Propaganda Fascista", Theodor Adorno reflete sobre a base psicológica de massa do fascismo. Dentro dessa psicologia, ele identifica uma lógica de "ampliação" do ego, que se relaciona diretamente com a estrutura do preconceito. O fascismo depende de ligações afetivas, ampliadas pelo preconceito (uma ampliação que ocorre por meio da identificação com um líder).

Inserido no contexto da indústria cultural, o indivíduo não é mais visto como o sujeito modificador e determinante de suas ações, sendo apenas guiado pela ideologia que se manifesta através de propagandas enganadoras de formação de projetos ideais de vida. Visto que

O totalitarismo considera as massas não como seres humanos autodeterminados que decidem racionalmente seu próprio destino e que devem, portanto, ser tratados como sujeitos racionais, mas sim que ele os trata como meros objetos de medidas administrativas, ensinados, acima de tudo, a se autoanular e a obedecer ordens. (ADORNO, 2015, 142).

Em uma sociedade onde os indivíduos anulam suas individualidades, é favorecido o nascimento do culto à personalidade. Cultuar tem uma significação de venerar, reverenciar uma imagem de um ser como um modelo ideal a ser seguido. O culto à personalidade é fruto da indústria cultural que se utiliza dos meios que esta oferece para atingir seus fins específicos. Sem dúvida, "é na comunidade da mentira que os líderes e seus liderados se reúnem graças à propaganda" (ADORNO; HORKHEIMER, 2006, 238), o uso da propaganda através de: cartazes, banners, revistas, enfim, a mídia em geral é usado para exaltar as virtudes reais ou não de uma certa personalidade, promove e aumenta a probabilidade de não só uma, mais duas, três, centenas ou milhares de pessoas passarem a cultuar e reverenciar tal figura da sociedade. E serão as personalidades políticas as principais referências para o uso e estudo desse termo pelo autor frankfurtiano.

O que hoje presenciamos neste novo modelo de sociedade e novo projeto de indivíduo que se adapta a cada novo passo do avanço da geração tecnológica

Doutoranda em Educação pela UFC, na linha Filosofia e Sociologia da Educação.

Pesquisadora do Grupo "Educação, Teoria Crítica e Filosofia Contemporânea" (Cnpq). Brasileira, residente em Fortaleza-CE. Email: manubazik@hotmail.com

Professor Titular da FACED. Doutor em Ciências Sociais pela Universidade Estadual de

Campinas. Brasileiro, residente em Fortaleza-CE. Email: hluizrech@gmail.com

Doutoranda em Educação pela UFC, na linha Filosofia e Sociologia da Educação.

Pesquisadora do Grupo "Walter Benjamin e a Filosofia Contemporânea" (Cnpq). Brasileira, residente em Fortaleza-CE. Email: liafreitasoliveira@gmail.com 
é o culto a qualquer tipo de personalidade que se mostra como um modelo ideal a ser seguido e copiado. Através de uma propaganda personalizada, essencialmente não objetiva, Adorno (2015) percebe que a personalidade a ser seguida se coloca tanto como o homem pequeno e modesto quanto um líder de grande calibre. Este homem autoritário,

\begin{abstract}
em contraste com o fanático de velho estilo, esse último parece combinar as ideias e habilidades típicas da sociedade altamente industrializada com crenças irracionais ou anti-racionais. Ele é ao mesmo tempo esclarecido e supersticioso, orgulhoso de ser um individualista e sempre temeroso de não ser igual aos outros, ciumento de sua independência e inclinado a se submeter cegamente ao poder e à autoridade. (ADORNO, 1989, 1).
\end{abstract}

O culto à personalidade existe porque o indivíduo, ao anular sua individualidade, em um mundo regido pela razão intrumentalizada, busca incessantemente se satisfazer e resgatar ela às custas de outro que supostamente é melhor do que ele e que passa aquela imagem ideal, buscando uma identificação já que sua subjetividade se perde no mundo administrado. $A$ cultura de massa modela igualmente as pessoas, deixando pouco espaço para o individualismo autêntico, cabendo a este indivíduo a busca pela identificação para tornar-se pertencente a algo. Por isso, ao estampar a imagem de um ser patriota, honesto e humilde em todos meios de difusão, o grande líder mostra que todos os que seguirem também serão este ser que ele supostamente transmite. O temperamento autoritário carrega sempre as mesmas características: a fraqueza do ego, idealiza a autoridade e tende ao preconceito.

Para Adorno, o "totalitarismo significa desconhecer limites, não permitir nenhuma pausa para o fôlego, conquistar impondo dominação absoluta, exterminar completamente o inimigo escolhido" (2015,141). Nessa visão, o personagem que representa esse totalitarismo sente o mesmo, desconhece os limites e se impõe com força para manter seu poder. O que Adorno (1989) pretende é promover o entendimento dos fatores sociopsicológicos que tornam possível ao tipo autoritário ameaçar o posto do tipo democrático e individualista

Doutoranda em Educação pela UFC, na linha Filosofia e Sociologia da Educação. Pesquisadora do Grupo “Educação, Teoria Crítica e Filosofia Contemporânea” (Cnpq). Brasileira, residente em Fortaleza-CE. Email: manubazik@hotmail.com

Professor Titular da FACED. Doutor em Ciências Sociais pela Universidade Estadual de

Campinas. Brasileiro, residente em Fortaleza-CE. Email: hluizrech@gmail.com

Doutoranda em Educação pela UFC, na linha Filosofia e Sociologia da Educação.

Pesquisadora do Grupo "Walter Benjamin e a Filosofia Contemporânea" (Cnpq). Brasileira, residente em Fortaleza-CE. Email: liafreitasoliveira@gmail.com 
dominante em nossa civilização no último século e meio, assim como os fatores por meio dos quais essa ameaça pode ser contida. A análise progressista desse novo tipo antropológico, bem como de suas condições de crescimento, através de sua permanente diferenciação científica fortalecerão as chances de um contra-ataque genuinamente educativo.

Para diagnosticar esse caráter fascista, os autores Theodor Adorno, Else Frenkel-Brunswik, Daniel Levinson e Nevitt Sanford realizaram uma pesquisa empírica que tenta desvendar a inclinação do indivíduo a um perfil autoritário. Tais pesquisas desenvolveram o que os autores denominam de Escala- $F$ (fascista) para avaliar o nível de propensão a tais atitudes de caráter repressivo. A escala $F$ foi desenvolvida em formulários com 60, 45 e 40 itens. Else FrenkelBrunswik descreveu a estrutura das entrevistas usadas no estudo da personalidade autoritária. A entrevista procurou abranger as seguintes áreas: atitude ocupacional, indicadores socioeconômicos, religiosidade e dados clínicos (antecedentes familiares, relações e estrutura familiar, infância, sexualidade, indicadores sociais, educação, opiniões políticas, atitudes em relação às minorias e preconceitos raciais).

Os pesquisadores foram guiados por uma hipótese geral que afirmava que:

as convicções econômicas, políticas e sociais de um indivíduo muitas vezes formam um padrão amplo e coerente como que se estivessem ligadas por uma mentalidade ou espírito, e esse padrão é expressão de tendências profundas em sua personalidade. (ADORNO, 1989,144).

A pesquisa resultou em um conjunto de predisposições de atitudes específicas que são características da chamada síndrome autoritária. Os autores identificaram e descreveram nove características da personalidade autoritária que serviram de base para a escala $\mathrm{F}$, composta por nove características:

1) Convencionalismo - Aderência rígida aos valores convencionais da classe média e inflexibilidade nas atitudes.

2) Submissão autoritária - Atitude submissa e acrítica em relação às autoridades morais idealizadas do grupo interno.

Doutoranda em Educação pela UFC, na linha Filosofia e Sociologia da Educação. Pesquisadora do Grupo "Educação, Teoria Crítica e Filosofia Contemporânea" (Cnpq). Brasileira, residente em Fortaleza-CE. Email: manubazik@hotmail.com

Professor Titular da FACED. Doutor em Ciências Sociais pela Universidade Estadual de

Campinas. Brasileiro, residente em Fortaleza-CE. Email: hluizrech@gmail.com

Doutoranda em Educação pela UFC, na linha Filosofia e Sociologia da Educação.

Pesquisadora do Grupo "Walter Benjamin e a Filosofia Contemporânea" (Cnpq). Brasileira, residente em Fortaleza-CE. Email: liafreitasoliveira@gmail.com 
3) Agressão autoritária - Tendência a estar atento e a condenar, rejeitar e punir as pessoas que violam os valores convencionais.

4) Anti-intracepção - Oposição ao subjetivo, ao imaginativo, ao sensível.

5) Superstição e estereotipia - A crença nos determinantes místicos do destino do indivíduo; a disposição para pensar em categorias rígidas.

6) Potência e "tenacidade" - Preocupação com a dimensão domíniosubmissão, forte-fraco, líder-seguidor; identificação com figuras de poder; ênfase exagerada nos atributos convencionais do ego; afirmação exagerada de força e resistência.

7) Destrutividade e cinismo - Hostilidade generalizada, difamação do humano.

8) Projetividade - A disposição de acreditar que coisas selvagens e perigosas acontecem no mundo; a projeção para fora de impulsos emocionais inconscientes.

9) Sexo - Preocupação exagerada com "acontecimentos sexuais". (ADORNO, 1969, 228).

Dessa forma, percebemos que a personalidade autoritária é caracterizada por uma extrema obediência e respeito inquestionável e submissão à autoridade de uma pessoa externa a si mesmo, o que se concretiza por meio da opressão de pessoas subordinadas. O caráter autoritário carece de discernimento, reflexão, especulação e fantasia, deseja "líderes poderosos", é obediente e respeita as autoridades. Através da Escala F, podemos citar diversos traços característicos dessa estrutura de personalidade: convencionalidade, submissão autoritária, impulso por poder, robustez, destrutividade e projetividade. A maior expressão dessa escala são os líderes de regimes autoritários, o líder fascista.

A estetização do político favorece, através de uma propaganda personalizada, apresentar o líder fascista como uma grande promessa de algo melhor. Ao falar de seus próprios defeitos psicológicos ele busca uma similaridade com seus seguidores, falando aquilo que eles querem ouvir. "Eles atuam de forma vicária por seus ouvintes desarticulados ao fazer e dizer o que os últimos gostariam, mas não conseguem ou não se atrevem a tal. [...] Os agitadores fascistas são tomados a sério porque arriscam a se passar por tolos" (ADORNO, 2015, 145).

Contra essa imagem do fascismo que ainda paira sobre nossas cabeças é urgente uma politização da arte, almejada por Walter Benjamin (1936), pois

Doutoranda em Educação pela UFC, na linha Filosofia e Sociologia da Educação.

Pesquisadora do Grupo “Educação, Teoria Crítica e Filosofia Contemporânea” (Cnpq). Brasileira, residente em Fortaleza-CE. Email: manubazik@hotmail.com

Professor Titular da FACED. Doutor em Ciências Sociais pela Universidade Estadual de

Campinas. Brasileiro, residente em Fortaleza-CE. Email: hluizrech@gmail.com

Doutoranda em Educação pela UFC, na linha Filosofia e Sociologia da Educação.

Pesquisadora do Grupo "Walter Benjamin e a Filosofia Contemporânea" (Cnpq). Brasileira, residente em Fortaleza-CE. Email: liafreitasoliveira@gmail.com 
somente a arte orientada para fins de resistência e emancipação podem fazer frente aos abusos que são cometidos pela estetização que favorece 0 nascimento e a permanência de figuras autoritárias. O estudo acerca do fascismo e da personalidade autoritária é uma exigência para que possamos ficar atentos a qualquer manifestação dessa ordem, no intuito de seguir na contramão no menor indício de sua aparição.

\section{CONCLUSÃO}

A indústria cultural, no interior do fascismo, domestica imagens e sons para captar a subjetividade dos indivíduos e estes entrarem no estágio de passividade. O espetáculo produzido pelos mass media propaga uma ideologia que mascara a sensação de liberdade. Dessa forma, o indivíduo não é mais livre para decidir, mas pensando que assim o faz se entrega aos ideais de um grupo que the fornece pertencimento. A identificação do sujeito aos líderes fascistas se dá pela falta de individualização que o mundo administrado é capaz de fomentar.

O estudo acerca da origem do fascismo em Walter Benjamin e do conceito de personalidade autoritária em Theodor Adorno fornece inspiração para investigações nessa área, devido a ameaça constante que as sociedades contemporâneas sofrem por tendências regressivas. É preciso ficar alerta a todo e qualquer tipo de sinalização autoritária para que possamos evitar novos extermínios, apesar deles eclodirem diariamente no mundo inteiro. O estudo acerca do fascismo nos possibilita entender questões como crimes de ódio e violência.

Em uma sociedade que tende à barbárie é importante levantar questões que nos auxilie na construção de um pensamento que possa resistir às ideologias fascistas, pois mesmo sendo irracionais elas possuem uma aplicabilidade, fato que aponta para diversos momentos de nossa história e até nos dias de hoje tais ideias se mantêm vivas.

Doutoranda em Educação pela UFC, na linha Filosofia e Sociologia da Educação. Pesquisadora do Grupo “Educação, Teoria Crítica e Filosofia Contemporânea” (Cnpq). Brasileira, residente em Fortaleza-CE. Email: manubazik@hotmail.com

Professor Titular da FACED. Doutor em Ciências Sociais pela Universidade Estadual de

Campinas. Brasileiro, residente em Fortaleza-CE. Email: hluizrech@gmail.com

Doutoranda em Educação pela UFC, na linha Filosofia e Sociologia da Educação.

Pesquisadora do Grupo "Walter Benjamin e a Filosofia Contemporânea" (Cnpq). Brasileira, residente em Fortaleza-CE. Email: liafreitasoliveira@gmail.com 
Como já afirmava Benjamin, no mundo onde prevalece a estetização é preciso abrir espaço para a politização da arte, utilizar-se da técnica e dos meios tecnológicos, modificando suas condições de produção e realização, para que estes atuem em prol de uma mudança significativa das relações sociais mediatizadas. O ideal fascista que prega e propaga o ódio mascarado de "solução" deve ser eliminado dentro de sociedades democráticas, sendo necessário uma nova política dentro dessa era tecnológica que não favoreça atos destrutivos, mas que fortaleça a autonomia dos indivíduos em prol da emancipação.

\section{REFERÊNCIAS}

ADORNO, Theodor W; FRENKEL-BRUNSWIK, E; LEVINSON, D. J; SANFORD, R. N. A personalidade autoritária. Traduzido por Francisco Rüdiger de acordo com a versão editada em Critical Theory ana Society - A Reader, organizado por Douglas Kellner e Stephen Bronner. Nova York: Routledge, 1989.

ADORNO, Theodor W; FRENKEL-BRUNSWIK, E; LEVINSON, D. J; SANFORD, R. N. The Authoritarian Personality, New York, Norton Library, 1969.

ADORNO, Theodor W. A indústria cultural. In: COHN, Gabriel (org.). Theodor W. Adorno. São Paulo: Ática, 1986. p. 92-99.

Educação e emancipação. Tradução Wolfgang Leo Maar. Rio de Janeiro: Paz e Terra, 1995a.

Ensaios sobre psicologia social e psicanálise. Tradução: Verlaine Freitas. 1ํㅡ. ed. São Paulo: Editora Unesp, 2015.

Indústria cultural: o esclarecimento como mistificação das massas. In: Dialética do Esclarecimento. Tradução de Guido A. de Almeida. Rio de Janeiro: Jorge Zahar Editor, 2006.

Minima Moralia: reflexões sobre a vida danificada. Tradução de Luiz Eduardo Bicca. São Paulo: Ática, 1992.

Doutoranda em Educação pela UFC, na linha Filosofia e Sociologia da Educação. Pesquisadora do Grupo "Educação, Teoria Crítica e Filosofia Contemporânea" (Cnpq). Brasileira, residente em Fortaleza-CE. Email: manubazik@hotmail.com 
. Notas sobre o filme [1966]. In: Cohn, Gabriel (org.). Theodor W. Adorno. São Paulo: Ática, 1986. p.100-107.

BENJAMIN, Walter. Magia, técnica arte e política: ensaio sobre literatura e história da cultura. Tradução de Sérgio Paulo Rouanet. São Paulo: Brasiliense, 1994. (Obras escolhidas; v. 1).

Rua de mão única. Tradução: Rubens Rodrigues Torres Filho e José Carlos Martins Barbosa. São Paulo: Brasiliense, 2012.

A obra de arte na era da sua reprodutibilidade técnica.

Organização e apresentação Márcio Seligmann-Silva; tradução Grabiel Valladão Silva. Porto Alegre: L\&PM, 2013.

COUSINS, Mark. História do Cinema: dos clássicos mudos ao cinema moderno. Tradução: Cecília Camargo Bartalotti. São Paulo: Martins Fontes, 2013.

DUARTE, Rodrigo. Adornos: nove ensaios sobre o filósofo frankfurtiano. Belo Horizonte: Ed. UFMG, 1997.

FREUD. Sigmund. A psicologia de massas e a análise do eu e outros textos. Tradução: Paulo Cezár de Souza. São Paulo: Companhia das letras. 2011.

GEADA, Eduardo. 0 imperialismo e o fascismo no cinema. Lisboa: Moraes Editores. 1977.

HOBSBAWM, Eric. A era dos extremos - o breve século XX: 1914-1991. (Tradução de Marcos Santarrita). São Paulo: Companhia das Letras, 1995.

JUNGER, Ernst. A mobilização total. Natureza Humana: Revista de Filosofia e Psicanálise, São Paulo, v. 4, n. 1, p. 189-216, jun. 2002. Disponível em: http://pepsic.bvsalud.org/scielo.php?script=sci_arttext\&pid=S151724302002000100006. Acesso em: 20 abr. 2021.

LÖWY, Michel. Walter Benjamin: aviso de incêndio - uma leitura das teses "Sobre o conceito de história". Tradução de Wanda Nogueira Caldeira Brant. São Paulo: Boitempo, 2005.

A estrela da manhã: surrealismo e marxismo. Tradução: Eliana Aguiar. São Paulo: Boitempo, 2018.

Doutoranda em Educação pela UFC, na linha Filosofia e Sociologia da Educação. Pesquisadora do Grupo "Educação, Teoria Crítica e Filosofia Contemporânea" (Cnpq). Brasileira, residente em Fortaleza-CE. Email: manubazik@hotmail.com

Professor Titular da FACED. Doutor em Ciências Sociais pela Universidade Estadual de

Campinas. Brasileiro, residente em Fortaleza-CE. Email: hluizrech@gmail.com

Doutoranda em Educação pela UFC, na linha Filosofia e Sociologia da Educação.

Pesquisadora do Grupo "Walter Benjamin e a Filosofia Contemporânea" (Cnpq). Brasileira, residente em Fortaleza-CE. Email: liafreitasoliveira@gmail.com 